\title{
Theoretical Model for the Econometric Model Formalization of a Budget Execution of the Decentralized Territorial Collectivities
}

\author{
Amaïde Arsan Miriarison TSIKOMIA ${ }^{\star}$
}

\begin{tabular}{l}
\hline \multicolumn{1}{c}{ A R T I C L E I N F O } \\
\hline Article history: \\
Accepted March 2021 \\
Available online April 2021 \\
\hline JEL Classification \\
C01, B41, H72 \\
Keywords: \\
Local Public Administration, \\
Budget of decentralized territorial \\
communities, Public finances, \\
Economic modeling, Numerical \\
simulation
\end{tabular}

1. Introduction

At the end of the 1980, the decentralization was a priority for many developing countries. This decentralization concerns the transfer of competence from the State to elected representatives of local authorities, or appointed in the event of administrative and financial inefficiency. From the point of view of the overall dynamics of the socio-political and macroeconomic reforms undertaken, decentralization is perceived as a new approach to local development, which takes in charge of their own needs and their mobilizable resources.

Madagascar is rather decentralized, to achieve medium and long-term development prospects. Within the local public administration (APUL), for the sake of equity, the State, through the decentralization process, grants financial autonomy and budgetary support, through the fiscal equalization system. However, the incessant political and economic crises induce an insufficiency and the fragility of the national economy, even local.

Until 2005, the practice phase of the means budget, the budget of the decentralized territorial communities is established on the basis of the ex-ante budget execution. It was from this year that the reform of public finances and the application of the program budget was adopted at the level of decentralized territorial communities.

The Municipalities in Madagascar have no budget prediction model and applied financial analysis method. They thus come up against a limited rationality of their forecasts. We can then speak about the Rationalization of Budget Choice (RCB). Hence results-based management (GAR), which is a method of streamlining government management and budget performance.

This is how a management of the public expenses, planned medium-term, where Setting of the Expenses Medium-term, (CDMT) oriented toward the results is adopted by the Malagasy State.

This is how the public expenditure management, planned for the medium term, where the Medium-Term Expenditure Framework (CDMT), oriented towards results, is adopted by the Malagasy state. 
This is why it is preferable that the municipal budget being established by a reliable method, using an adapted and parameterized prediction model, knowing that all economic and political variables will be considered.

Since the 1970, in developed countries, various budget prediction and simulation models have already appeared. Empirical studies on public choice theory have also shown that the behavior of local elected officials influences the APUL, both at the level of the electoral cycle, and at the level of partisan politics.

The modeling of cash holdings was excluded ("...] For the first time, a systematic analysis of municipal financial behavior becomes possible. The lock on access to information is thus lifted, at least in part. Indeed, the centralization of local finances relating only to total expenditure and revenue, the study by collective consumption function, potentially the richest, remains excluded. Access to large national statistical files is nevertheless at the origin of a substantial enrichment of prior knowledge based until then on small unrepresentative samples, A. GUENGANT (2002) ") from this for reasons for the tendency of decision-makers of local elected officials to liquidate all expenses for the current year, operations for the month of December are not reliable for the analysis of the change in treasury, including operations for additional days of year $\mathrm{N}$ until January $15, \mathrm{~N}+1$.

Finally, this research was carried out on the basis of a retrospective study of administrative accounts and net treasury from 2002 to 2019, of the Urban Municipality of Toamasina - I (or CUT), which was a period of cyclical crisis of the political-economic in Madagascar. However, a preliminary remark is in order: the desynchronization of the electoral cycles (discordance of the ballots and the length of the mandates according to the nature of the political power of the local elected representatives) prevents from considering the Municipalities as a whole.

\section{Literature paper}

Despite the financial and administrative autonomy of the decentralized local authorities (or CTD), they are still governed by public finance rules. Public finance theory has always considered the State as a single (or homogeneous) entity. So, while complying with the same rules, the spatialization of the concept of public authorities can be extended to a decentralized representation of the administration, such as the famous "law of Wagner", of which we must consider the economic and budgetary constraints, the constraints spatial choices, the effects of externalities, or that, on a financial level, of the fiscal mobility of agents or taxpayers, ... P. H. Derycke, G. Gilbert (1988), according to A. Wagner, a positive relation exists between the part of the public expenses in the GDP and the level of development of the country, " [...] what translates the increasing necessity of the intervention regulationist of the State in a more and more complex society ". Taking this positive relationship into account in Wagner's law, local government budgets are thus encompassed by the following three components:

- structural components: which are the segmentation of the behaviors of the budget structure. The role of the investment section is essential from this point of view of local economic development. The modification of this structure, in particular in the Municipalities, contributes, by its action on the investment cycle, to determine the level and the evolution of the free funds (Let S: represent the structural treasury, B: represent the budgetary volume, I: represent the volume of investment and F: represent the volume of working. Then, the I/F report permits to measure the structure of the budget and its evolution) ;

- cyclical components: Of a different nature from the structural components, the cyclical variables are both multiple, and their effects vary according to the economic environment, and demographic variables, or the size of the Municipality and the local policy of the chosen one ;

- and accidental components: constituted by the economic crisis and political uncertainties. Indeed, only the direct effects on the budget components can be measured, that is to say those which have the same impact on the various elements of the budget headings of the local authorities. Hence, the " budget shocks variables".

\section{The municipal budget}

The municipal budget is the fundamental act of municipal management, because it determines, each year, all the actions that will be undertaken. It is both an act of forecasting and authorization (commitment to liquidate expenditure, collectable revenue). It is an act of forecasting: the budget constitutes a financial program evaluating the receipts to be collected and the expenditure to be made over a year. But the municipal budget is also an act of authorization: the budget is the legal act by which the mayor - the executive body of the local authority - is authorized to incur expenses voted by the Municipal Council.

\subsection{The budgetary constraints to the level of the decentralized territorial collectivities}

The decision-makers or the ministerial chief, approved by the piece of advice, are the proxy of the budget of the Township execution. In the setting of the fluctuation of the economic variables (inflation, variation of the income led by the crisis), The political decision-makers are submitted to budgetary constraints, to the budgetary management activity. 
In a decentralized economy, "the hard budget constraint" requires that local decision-makers perceive the totality of the gains and bear the totality of the financial burden entailed by their decisions, that is to say that the efficient allocation of resources requires that they internalize the gains and costs incurred from the execution budget. As McKinnon (1995) point out, " [...] a hard budget constraint is necessary for competition between communities to take place and to provide local decision-makers with the incentives to maximize the well-being residents".

On the contrary, it is possible that the Decentralized Territorial Collectivities (CTD), by respecting the rule of ex-post budgetary balance (forecast from the ex-ante $\mathrm{N}-1$ budget) has the possibility of transferring all or part of the charges to other agents outside the CTD. For example, the case of the responsibility assumption for CTD debts by the State, through an equipment or investment subsidy (G. Gilbert, F. Vaillancourt (2013), "[...] We find an identical situation of soft budget constraint in the model of Wildasin (1997) where the granting of additional allocations from the State can only benefit communities of a sufficiently large size so that in the event of financial difficulties, the cuts they would have to make in collective services would be so large that they would require additional aid from the State"), depending on the nature of the expenditure. We then speak of "budgetary externality" and "financial externality or fiscal externality", if the expenditure generates financial expenditure (in the case of loans). This externality then encourages the CTD to ask for more resources or to spend more (in the event of a surplus). We thus speak about "budgetary indiscipline" (fiscal indiscipline) because it places the CTD in front of a "soft" budget constraint (or constrained soft budget).

\subsection{Financing a municipal budget}

The financing of the local budget (Article ${ }^{\circ} 180$ to 236 the organic law $n^{\circ} 2014-020$, resources of the Townships in Madagascar are: the products of the local tax system coming from the local taxes or fiscal income, the non-fiscal income, the financial contests of the State and the intercommunality, the excess of the budgetary income, the loans to long and middle terms, and the dividend of the EPCI (Public establishment of an industrial and commercial nature) is assured in major part by the income descended of the local tax system, of the rights and various taxes of the public services, and of the royalties. Contrary to the developed countries, for example for France, whose CTD have a strong financial autonomy, G. Gilbert (2001), " [...] the various transfers to the local collectivities passed from 15\% of the budget of the state in 1980 to more of $19 \%$ in 1999 on this day, (...) is true for a large part to the decentralization of expertise ", funds of contest are very raised.

\section{Models}

The main objective of the models is to become aware of the multiple interdependencies, and to assess the cumulative effects of a phenomenon. According to ARMATTE (2005), "[...] Very generally, a model seeks to make intelligible a phenomenon perceived as complex, and / or to make experimentation, simulation and prediction possible. This dual use, as a representation of a certain reality and a blueprint for its study, is characteristic of the model in the modern science".

\subsection{The research of the explanatory elements}

To forecast budgeting, there are a number of methods that can be used, including mathematical modeling, index, normative projection, and equilibrium.

The first of these, the mathematical modeling process is based on the use of economic and mathematical models which allow a large number of interrelated factors which influence the budget items to be considered. They also allow leeway in determining the technique of budget forecasts, and choosing among several budget variants, the optimum corresponding to the accepted strategy for local socio-economic development.

The index or indicative method is based on various indicators characterizing the socio-economic development of the Municipality. This concept is also used to assess the quality of budget control, in order to improve the efficiency of the management of financial resources in the Municipality.

The normative method is based on progressive and financial, budgetary standards, the standards necessary to calculate budget revenues on the basis of established tax rates, and a number of macroeconomic factors, such as tax burden, deficit budget, municipal debt... This method was used to determine the budgetary capacity to pay.

The equilibrium method makes it possible to maintain the balance between revenue and expenditure, and to maintain the measure of the budget structure (investment and operating ratio) to achieve structural treasury at time $t$.

The evaluation from budget data, carried out in the past, when the trends of certain forecasting processes have not been well determined, the achievement gap too high, and it is necessary to use special calculations, having recourse to statistical forecasting and economic prediction methods. 


\subsection{The determinants of forecasting and budget execution}

An economic study can reveal many similarities between the determinants of cash in public administrations and those of companies, thus allowing a comparison of management technique ("...] The pessimistic findings to which lead to the various articles calling a possible analogy between management the APUL and management of the enterprises, lean on a strong divergence of the objectives of each (A. Guengant [1985], P. Rich Person [1986], R. Danziger [1987]"). However, the management of the free funds constitutes one of the rare elements for which the short-term intentions between APUL and enterprises are identical. This likeness of the objectives is often accompanied with similar methods"), the same cannot be true for an approach to Local Authorities. There are several reasons for this statement:

- each sector of activity to which the firms are attached has its own operating cycle, thus explaining most of the disparities in the treasury of companies, but which cannot be applied to local authorities, whose activity is relatively homogeneous;

- conversely, the size of the Municipalities (the volume of its population, the area in terms of housing tax, and the level of existing infrastructure) seems to be a criterion for determining the level of the budget, while it is making no sense for a business. Under such conditions, a search for internal determinants cannot be carried out on the basis of a comparison with companies, but must be deduced from a statistical analysis. This will not only highlight the determinants common to all the Municipalities, but also to refine the relations according to a double physical criterion (depending on size, and financial (opposition value/structure)).

Thanks to the work of J. Bouinot in 1997, the operations of local authorities can be subdivided into three elements:

- the first (rigid treasury) groups together transactions for which the deadlines and amounts are perfectly known when the budget is drawn up;

- the second (controllable treasury) brings together flows for which neither the deadlines nor the amounts are perfectly known, but for which the uncertainty concerning them can be partly contained by rigorous management;

- the last (random treasury) includes all transactions whose fluctuations are completely unpredictable.

\subsubsection{The delays}

The gap between the wanted treasury and the efficient treasury can be interpreted as the reflection of the different delays of which is "victims" the fluxes of local treasuries.

The effect of the engagement delay on the cash balance supposes a particular behavior of the local collectivities. These last anticipate, according to their initial budget and the calendar of realization of the investments or working (PTA of the budget programs), a variation of their resources and the collection or the recovery of the funds necessary to the moment required.

The effect of the accounting delay can be supposed constant short-term: indeed, if the public accountant is only considered like a mediator. In fact, the accounting delay is independent of the delay organizer. It is the representation of the technical delay necessary to the treatment of the orders received. The accounting services don't have for as much a solely technical behavior: they cannot allow any negative cash balance. This rigidity drags, when the level of cash balance is raised little, a growth important of the accounting delay, having for consequence an artificial maintenance of the treasury level. This situation has the tendency to disappear with the use of a planning of payment, short-term, to one instant given.

The effect of the delay organizer on the cash balance of treasury is probably the most difficult, because least known to model. Of the fact, a length of three to four times superior to the one of the accounting delays. This delay can be explained yet by two essential motives. One, technique, permits to consider the treatment delay of the operations by the local financial services. As well as for the accounting delay, this delay can be considered like a constant; the other corresponds to the organizer's attitude voluntarist, that uses this margin of operation like a regulation instrument of the treasury fluxes, this in an optimal management optics. If this last objective is already reached, the organizer's gait consists of searching for the treasury of short term, the steadiest possible.

The balance of treasury or free fund led by the accountant organizer should be therefore function, to the cash balance wanted for motive of precaution, results a triple preoccupation of the local elected (economic and social environment, mastery of the internal resources and mistakes anticipated of forecast). The cash balance wanted for motive of transaction directly depends on the volume estimated of the budgetary operations. The exactness of the forecasts is here of a fundamental importance, since all mistake, while obliging the local persons responsible to react, include a cost for the Township.

\subsubsection{Accidental components}

The modelling of the accidental components or the "variable fiscal shock" that constitutes the globalization of the endowments, the law of the decentralization and the trivialization of the subsidies, do not cause any particular problem. 
One of the stakes of the best implication of the local collectivities in the correction of the public accounts resides in the capacity of the State to drive, simultaneously, the decrease programmed of its financial contests, and the one of the working global endowments, that is going to affect the model of budgetary balance of the local collectivities. The government's choice to reduce or to abandon the remittance of its contests and endowment during a fiscal year, risk then to drag a receding troubling of the raw saving of the local collectivities. Then, the Townships must make budgetary choices, to compensate the reduction of the State's subsidies and endowments.

\subsubsection{The structural components}

The structural components are the behaviors' segmentation of the budgetary structure. The role of the investment section is from that primordial point of view of the local economic development. The structural components have therefore a goal to see the measure of the budgetary structure and its long-term evolution, with $r=\frac{I}{F}$ : ratio of structure, I: volume of investment and F: operating volume. The structural treasury or structural free fund (FLS) is function of the budgetary volume and the ratio of structure. with $F L S=F L S\left(B^{t},\left(\frac{I}{F}\right)\right)$ : structural treasury and $\mathrm{B}^{\mathrm{t}}$ : budget volume at period of financial year $t$.

\subsubsection{The cyclical components}

The cyclical components are both multiple, and their effects vary depending on the economic environment, demographic variables or the size of the Municipality, and the local politics of elected officials. Indeed, only the direct effects on the components of the treasury can be measured, the long-term effects, such as the gradual penetration of the electoral cycle.

\subsubsection{The inflation rate}

The theoretical role of the inflation rate on the components of the treasury is multiple:

- the real treasury effect (Pigou-Patinkin effect) depreciates the purchasing power of local government cash: efforts to reduce cash should therefore be accentuated, during a period of growth in price;

- continuous disinflation, by increasing the burden on which local elected representatives are forced to draw, to maintain a balanced budget, based on previous years. An often-naive anticipation of inflation contributes, in a period of disinflation, to an increase in working capital and its components, and to naive forecasts of budgetary expenditure.

\subsubsection{The economic growth rate}

In a changing economic environment, inflation and economic growth are two things to remember in a budget forecast. Despite the autonomy of the Territorial Communities, their investment expenditure budgets must always be indexed to the rate of economic growth, given the various local productive sectors, whether from a micro or macroeconomic point of view, in order to take in consideration of the economic growth cycle. Investments.

\subsubsection{Budgetary behaviors according to the size of the municipalities}

Two behaviors concerning management of treasury are revealed by our analysis: the first, bound to the financing of the investments by the subsidies received of the State, calculated in relation to the number of population, seems common, in different proportions, to all the Municipality; the second, linked to the fiscal potential where small municipalities are less flexible than that of large municipalities.

The endowment for every township is calculated by the synthetic indication (ISj) of the Township considered $\mathrm{j}$ on the basis of the inhabitants' total number of all Townships and on the basis of the depth poverty indication (IPj).

For example, (B. Dafflon, 2012): "[...] 60\% on the basis of the population number $H$ of the Common $j$ in the total of the inhabitants of the 349 Townships and 40\% on the basis of an indication of poverty depth predefined".

$$
I S_{j}=\left(0,60 \times \frac{H_{j}}{\sum_{j=1}^{349} H_{j}}\right)+\left(0,40 \times \frac{I P_{j}}{\sum_{j=1}^{349} I P_{j}}\right)
$$

The amount of the endowment for a Common $j$ is

$$
M_{j}=10 \text { millions CFA forfait par Commune }+\left(\frac{I S_{j}}{\sum_{j=1}^{349} I S_{j}}\right) \times \text { Re liquat }
$$

Under these conditions, too rapid growth in tax revenues would create a real trauma that could undermine the political objective. Obviously, in the dynamic of reform and expansion of the city, local taxes 
appear as an instrument for simulating economic dynamism, placed at the service of local elected officials, with a view to improving the living conditions of their populations.

\subsubsection{The electoral cycle or cyclical determinant}

Part of the budget evaluation or execution deviations may correspond to possible cycles. The external variables that can cause seasonal behavior are:

- local electoral deadlines, for supra-annual cycles (Period of the mandate of the elected);

- and various habits and obligations in the distribution of operations during the various financial years, for the infra-annual cycles.

The effect of an electoral cycle on local finances has often been considered decisive in local models, despite the difficulties of assessment linked to the existence of many other politico-economic stimuli (recovery or stabilization plan, decentralization,...) and the insufficient number of complete cycles covered (in large cities, particularly strategic for the State, the completed mandate of elected officials is two or three years being a maximum).

However, A. Guengant (1984) integrates the electoral cycle directly into the explanation of the treasury, through the other budgetary components. If we stick to this analysis, Local Authorities have a tendency to increase certain expenses, in particular equipment efforts, and to reduce the tax burden in the run-up to an election. With a view to constant growth, such a policy requires a mechanism for the intertemporal transfer of financial resources: the budgetary balance constraints prohibiting the use, as only the State can do, of regulation by deficits, only the cash is in a position, at the macroeconomic level, to perform this function. The level of the FR during the first years of a cycle is therefore artificially inflated by excess tax revenues, then, as the deadline approaches and the deadlines given for completion, the financing of investments, which are more numerous, effected by a sustained drain on cash, accentuated by tax relief.

According to A. Gillouard (1982), in his econometric analysis of a municipal investment function, the effect of the electoral cycle on the treasury of communities increases, after the election, to maintain the profitability of local administration activities, and decreases at the time, before and after the ballot, because of the maintenance of fiscal pressure, and the increase in investment spending, to win the next ballot.

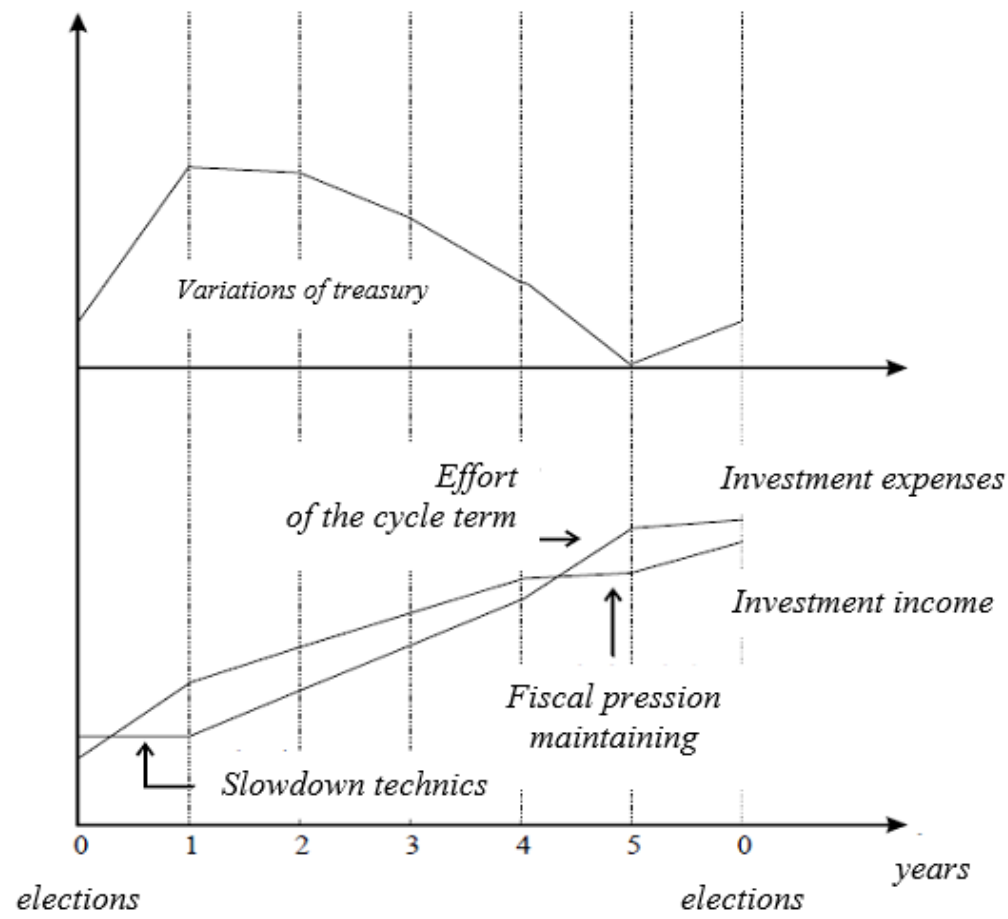

Figure 1. Effect of the electoral behavior on variations of treasury

Source: A. Gillouard, "Econometric analysis of a municipal investment function", communication to the round table on local public finances of CEREVE, November 25, 1982, University Paris-Nanterre, 1982, 20 pages.

\section{Theoretical models}

The decomposition of the explanatory factors which precedes, leads us to a global writing, where the explanatory variables are of three types:

- a macroeconomic variable representative of the economic situation: the inflation rate, economic growth and tax pressure rate;

- budgetary variables representing the financial situation of Local Authorities: total expenditure, total income, subsidies and endowments, and time of treasury depletion (where the time between the waiting 
time for the free funds existing at the General Treasury, for provide an instance for the payment of expenses);

- a variable representing the effectiveness of the treasury forecasts and the management of the Local Authority: cash desired in order to standardize the assessment procedures of several Municipalities.

\subsection{The functions of theoretical models}

The budgetary operations $(p)$ of one period t is equal to $\sum_{i=1}^{n}\left|p_{i}^{t}\right|$

In the beginning of the year, the sections working $(F)$ and the sections investments $(I)$, the sum of the operations is hopeless.

Let: $F \cap I=\Phi, F \cup I=B$ et $\left\{\begin{array}{l}\sum_{\mathrm{i} \in \mathrm{I}} \mathrm{p}_{\mathrm{i}}=0 \\ \sum_{\mathrm{j} \in \mathrm{F}} \mathrm{p}_{\mathrm{j}}=0\end{array}\right.$ with $B$ : budget

In phase of execution of the budget, the free fund $(F L)$ or the clean treasury of the period $t$ is then the sum of the operations: $\sum_{i=1}^{n^{\prime}}\left|R_{i}^{t}\right|$ et $\sum_{j=1}^{n^{\prime \prime}}\left|D_{i}^{t}\right|$

Thus $F L^{t}=\sum_{i=1}^{n^{\prime}} R_{i}^{t}-\sum_{j=1}^{n^{\prime \prime}} D_{i}^{t}$. Between the two periods $\mathrm{t}_{0}$ and $\mathrm{t}_{1}, F L$ is written :

$F \boldsymbol{L}^{t_{1}}=F \boldsymbol{L}^{t^{0}}+\left(\sum_{i=1}^{n^{\prime}} \boldsymbol{R}_{i}^{t_{1}}-\sum_{j=1}^{n^{\prime \prime}} \boldsymbol{D}_{i}^{t_{1}}\right)$

$F L^{t 0}$ : the free fund in the beginning of period

\subsection{Budget forecast}

The budget $B_{k}, k=1 . . k$ with $k$ the ex-post budget, is evaluated on the basis of budget executions $C A_{j}$, $j=0 . . j$ with $j$ the ex-ante years.

Budget expenditure $\left(D_{k}\right)$ is made up of compulsory expenditure $\left(D O_{i}\right)$ and other expenditure $\left(D A_{i}\right)$. The sum of the $n$ expenditures of the budget $k$ is then:

$$
\sum_{i=1}^{n} D_{k}=\sum_{i=1}^{n}\left|D O_{i}\right|+\sum_{i=1}^{n}\left|D A_{i}\right|
$$

\subsection{Forecasts of compulsory expenditure}

Compulsory expenses are made up of:

- salaries and salary accessories (permanent staff or not): $S_{k}$

- fuels and lubricants (for removal garbage and other service requirements): $C_{k}$

- payable debts (compulsory payment arrears) and deficit coverage): $A R R_{k}$

$D O_{i}=\sum_{i=1}^{n}\left|S_{i}\right|+\sum_{i=1}^{n} C_{i}+A R R_{j-1}$

Considering the social recruitment of the elected official in the infra-annual period, the payroll expenditure (compulsory expenditure) is increased by the recruitment workforce forecast for period $k$.

$S_{k}=\left(S_{j-1}+\left(S_{j-1} \times\right.\right.$ Augsal $\left.\left._{k}\right)\right)+$ recruelu $_{k}$

$S_{j-1}=S_{j-1}\left(1+\right.$ Augsal $\left._{k}\right)+$ recruelu $_{k}$

Augsal $_{k}=\frac{\sum_{j=1}^{J} \text { Augsal }_{j}}{J}$ and $S_{j-1}=\sum_{i=1}^{12} S_{i}{ }^{j-1}$

$\operatorname{Augsal}_{k}$ : average annual growth rate of the pay base

recuel $u_{k}$ : amount of the budget allocated for the staff to be recruited by the elected official

For $C_{i}$, the price variation is considered relative to the average price of period $j-1$, i.e. pcarbur $_{j-1}$ 
pcarbur $_{j-1}=\frac{\sum_{i=1}^{n} \text { pcarbur }_{j}-1}{n}, \mathrm{n}=1 . .12$
$C_{k}=C_{j-1}+\left(C_{j-1} \times\right.$ pcarbur $\left._{j-1}\right)$
$C_{k}=C_{j-1}+\left(1+\right.$ pcarbur $\left._{j-1}\right), C_{j-1}=\sum_{i=1}^{12} C_{i}^{j-1}$

The territorial collectivities in Madagascar don't subscribe a loan, and the organic law of the law of the finances (LOLF), from the year 2005 did not opt for the budget deficit, that is than only the amounts expenses that the free fund can cover in progress, must be paid. Then, the mistakes of engagement of expenses or the unpaid expenses of the year $j-1$ is equal:

$A R R_{k}=\sum_{j=1}^{J} A R R_{j-1}$

The amount is already due. Hence, they are not influenced by the explanatory factors.

\subsection{The forecasts of other expenses}

The other expenses $(D A)$ are evaluated by the factors of structural conjunctures and component of shock or accident.

Let $E L U$ be the variable of the electoral cycle. According to four criteria, the expenditure will depend on the following elements:

(a): If $k$ is pre-election, $k=k-t$ with $t$ election period. $E L U_{k}$ achieves economic growth: structure ratio

$$
r=\frac{I}{F} \text {, investment, and revenues increase. }
$$

(b): If $k$ is supra annual, $k=k+t_{i}$ with $t_{i}$ term of office after election, $E L U_{k}^{t_{o}}$ carries out stable investment operations, stable revenues: a technical slowdown.

(c): If k is infra-annual, ranging from $k=k+$ ( to to $t_{n-1}$ ) with a new election period, l' $E L U_{k}^{t_{o}}{ }^{\grave{a}} t_{n-1}$, increases revenue (high fiscal pressure), operating expenditure (social recruitment, procurement of supplies to speed up the administrative and technical service...). Hence local economic growth driven by increased productivity.

(d): If $k$ is a period of cessation of the $E L U_{k}$ activity, that is to say the presence of an authorizing officer appointed by the central state. At this stage, the objective is to make straight out local fiscal policy, and in favor of the partisan policy orientation of that of the central power. L' $E L U_{k}^{t_{o}}$ à $t_{n-1}$, will then achieve an increase in revenue, through better monitoring of management control (especially grants and endowments), investments, new technical staff, and achieve the objective of developing the local economy. of (a) :

$D A_{k}=\sum_{i=1}^{12} D A_{i}^{j-1}+\left(\sum_{i=1}^{12} D A F_{i}^{j-1} \times\left(1+I N F L A_{k}\right)\right)+\left[\left(\sum_{i=1}^{12} D I_{i}^{j-1} \times\left(1+\right.\right.\right.$ CROISS $\left.\left._{k}\right)\right) \times$ effort $\left._{k}\right]$

CROISS: economic growth in period $k$ of the LOLF (calculated at constant currency or excluding inflation)

$D I_{i}^{j-1}$ : investment expenditure for year $j-1$

$D F_{i}{ }^{j-1}$ : operating expenses for year $j-1$

effort $t_{\text {: }}$ index of recovery to win the election in favor of the politics supporter the of the elected official. The minimum value is equal to the program budget target indicator object $_{G A R_{j}}$ - Indicateur d'évaluation $C A_{j-1}$ ) (indicator of evaluation), then

l' effort ${ }_{k} \geq\left(\right.$ object $_{G A R_{j}}$ - Indicateur d'évaluation $\left.C A_{j-1}\right)$. The indicatory $C A_{j-1}$ can also have an equivalent value of the PEFA $\mathrm{j}_{\mathrm{j}-1}$ (Public Expenditure and Financial Accountability).

$I N F L A_{k}$ : forecast of the inflation rate for year $k$.

$I N F L A_{k}=$ IPC average $\mathrm{j}_{-1}(1+$ inflak), with infla $k$ a forecast of growth of the IPC (value of the forecast from the LOLF). 
$I P C$ : consumer price index

of (b) : $D A_{k}=\sum_{i=1}^{12} D A_{i}^{j-1}+\sum_{i=1}^{12} D F_{i}^{j-1}+\sum_{i=1}^{12} D I_{i}^{j-1}$.

One considers the technical slowing.

of (c) : $D A_{k}=\sum_{i=1}^{12} D A_{i}^{j-1}+\left(\sum_{i=1}^{12} D F_{i}^{j-1} \times\left(1+I N F L A_{k}\right)\right)+\left(\sum_{i=1}^{12} D I_{i}^{j-1} \times\left(1+C R O I S S_{k}\right)\right)$

In the infra-annual cycle phase, the elected representative will execute the local political objective of development focused on the general economic policy (PGE) of the central State.

of (d): The expenditure corresponds to the pre-election expenditure forecasts. The current (appointed) authorizing officer is a person who will prepare the future elections in favor of the central power. Hence, the equations $(\mathrm{d})=(\mathrm{a})$.

\subsection{Revenue forecasts}

The jaws effect between spending and government revenue has forced us to assess the expenses first. The golden rule, balance between, the DF (Functionary costs) and RF (Functionary revenue), the ID (investment expenses) and RI (investment income) must be maintained.

So, we have:

$$
\sum_{i=1}^{12} D I=\sum_{i=1}^{12} R I \text { et } \sum_{i=1}^{12} D F=\sum_{i=1}^{12} R F
$$

The income is several kinds. Taking into account the particularity of decentralized local authorities (financial autonomy and fiscal equalization), the revenue forecast is established in two stages:

- the forecast from a regression line derived from the budget situation $C A_{j-1}$ to $C A_{j}$. We only apply the calculation of revenue $R_{k}$ corresponding to expenditure $D_{k}$ for each section of the budget and nature of the budget account from this equation.

- and calculations based on explanatory factors, and adjustments will be made to compensate for imbalances between sections of the budget.

\subsection{Investment income}

The electoral cycle always has major effects on revenue collection at the level of decentralized local communities. So : of $(\mathrm{a})$ :

$R I_{k}=\sum_{i=1}^{12} A I_{i}^{j-1}+\sum_{i=1}^{12} S U B_{i}^{j-1}+Q I^{j-1}, \operatorname{avec}_{i} S U B_{i}^{j-1} \geq 0$

$A I_{i}^{j-1}$ : the sum of the other investment income $(\mathrm{AI}=\mathrm{RTEE}+\mathrm{RLT}+\mathrm{RLB}+\mathrm{Loan}$, with Loan $=0 . \mathrm{AI}$ :

Other investment income; RTEE : Revenue from water and electricity works ; RLT : Revenue on sale and rental of communal land ; RLB : Revenue on sale and rental of municipal buildings).

$S U B_{i}^{j-1}:$ the sum of the equipment and investment subsidy.

$Q I^{j-1}$ : the sum of the part of the budget balance for period j-1 allocated to the investment section.

$Q I^{j-1}=$ Reliquat $^{\mathrm{j}-1} \times$ TIrepartition $_{k}$, TIrepartition $_{k}$, the distribution rate of the overall balance,

to compensate for the investment income.

For the case where the authorizing officer is a supporter of the current power, the accidental component $S U B_{i}^{j-1}>0$ because they are already entered in the state budget, and the payment would probably be safe. Otherwise, there is a risk $S U B_{i}^{j-1} \geq 0$.

The $\mathrm{R}_{\mathrm{k}}$ vary two conditions :

- elected or authorizing officer in favor of the current power, we have:

$R I_{k}=\sum_{i=1}^{12} A I_{i}^{j-1}+\sum_{i=1}^{12} S U B_{i}^{j-1}+Q I^{j-1}$

- elected or authorizing officer is not a supporter of the current power, we have:

$R I_{k}=\sum_{i=1}^{12} A I_{i}^{j-1}+Q I^{j-1}$

of (b): phase considered as start and technical slowdown, the equations of (b) is equivalent to that of

(a) because there is no change in the revenue situation (stable revenue). 
from (c): increased revenue

- elected or authorizing officer in favor of the current power, we have:

$R I_{k}=\sum_{i=1}^{12} A I_{i}^{j-1}+\sum_{i=1}^{12} S U B_{i}^{j-1}+Q I^{j-1}$

$\sum_{i=1}^{12} A I_{i}^{j-1}=\sum_{i=1}^{12} A I_{i}^{j-1}+\sum_{i=1}^{12} A I_{i}^{j-1} \times$ tauxfiscal $_{k}$

$\left.\sum_{i=1}^{12} A I_{i}^{j-1}=\sum_{i=1}^{12} A I_{i}^{j-1} \times(1+\text { tauxfiscal })_{k}\right)$

with rate of fiscal pressure of the organic law of the law of the LOLF finances

So : $R I_{k}=\sum_{i=1}^{12} A I_{i}^{j-1} \times\left(1+\right.$ tauxfiscal $\left.{ }_{k}\right)+\sum_{i=1}^{12} S U B_{i}^{j-1}++Q I^{j-1}$

- elected or organizer is not partisan of the present power, we have:

$R I_{k}=\sum_{i=1}^{12} A I_{i}^{j-1} \times\left(1+\right.$ CLtauxfiscal $\left._{k}\right)+Q I^{j-1}$

with CLtauxfiscal $_{k}$ : rate of fiscal pressure chosen by the elected. That is CLtauxfiscal $_{k} \geq$ tauxfiscal $_{k}$, otherwise the overall objective of development would contradict the general policy of the central state.

from (d): preparation for future elections, the tax rate is maintained at budget period $k-1$.

The other $A I_{k-1}$ recipes can then be identical for the $A I_{k}$ period. So, we have as follows:

- for the elected official or partisan of the current power:

$R I_{k}=\sum_{i=1}^{12} A I_{i}^{j-1}+\sum_{i=1}^{12} S U B_{i}^{j-1}+Q I^{j-1}$

- for the elected official or authorizing officer is not a supporter of the current power:

$R I_{k}=\sum_{i=1}^{12} A I_{i}^{j-1}+Q I^{j-1}$

\subsection{Operating income}

Functionary revenue $(R F)$ is the sum of tax revenue, in particular land revenue (property tax on built properties or IFPB and land tax or $I F T)$, other tax revenue $(A R F)$, other revenue $(A R)$, endowments $(D O T A)$ and balances transferred to revenue from operation $(Q F)$.

$Q F^{j-1}$ : the sum of the budget balance part for period $j-1$ allocated to the operating section.

$Q F^{j-1}=$ Reliquat $^{\mathrm{j}-1} \times$ TFrepartition $_{k}$, TFrepartition $_{k}$, the distribution rate of the overall balance to compensate for operating income.

The overall equation is written:

$R F_{k}=\sum_{i=1}^{12} I F P B_{i}^{k}+\sum_{i=1}^{12} \operatorname{IFT}_{i}^{k}+\sum_{i=1}^{12} A R F_{i}^{k}+\sum_{i=1}^{12} A R_{i}^{k}+D O T A_{i}^{j}+Q F^{j-1}$

However, the endowments are influenced by the electoral cycle. Previously, as in the case of investment income, if the authorizing officer is a supporter of the current power, this component accidental with DOTA $_{i}^{j-1}>0$ avec DOTA ${ }_{i}^{j-1}=$ DOTA $_{i}^{j-1} \times$ CROISS $_{K}$ because they are also already entered in the State budget, the payment would probably be safe. Otherwise, there is a risk $D O T A_{i}^{j-1} \geq 0$.

The part of the endowment also increases, following the increase in the state budget:

$\sum_{i=1}^{12}$ DOTA $_{i}^{j-1}=\sum_{i=1}^{12}$ DOTA $_{i}{ }^{j-1}+\sum_{i=1}^{12}$ DOTA $_{i}{ }_{i}^{j-1} \times$ CROISS $_{k}$

$\sum_{i=1}^{12}$ DOTA $_{i}^{j-1}=\sum_{i=1}^{12}$ DOTA $_{i}{ }_{i} \times\left(1+\right.$ CROISS $\left._{k}\right)$ 
The endowments are calculated as follows:

Let $D O T A_{t}^{T}$ : probable total endowment, with:

$I S_{j}=\left(T_{1} \times \frac{H_{j}}{\sum_{j=1}^{n} H_{j}}\right)+\left(T_{2} \times \frac{I P_{j}}{\sum_{j=1}^{n} I P_{j}}\right)$

$D O T A_{t}^{T}=$ Montant forfait par Commune $+\left(\frac{I S_{j}}{\sum_{j=1}^{n} I S_{j}}\right) \times$ Re liquat

the specific amount sum for each commune

$H_{j}$ : number of population of a Municipality $j$

$n$ : total number of Municipalities in the country

$I S_{j}$ : ynthetic index of a Municipality $j$

$I P_{j}$ : depth of poverty index

$T_{1}$ : distribution rate in relation to the population number of a Municipality $j$

$T_{2}$ : distribution rate in relation to the poverty of a Municipality $j\left(T_{2}=100 \%-T_{1}\right)$

For the fundamental income : $I F P B^{k}=I F P B^{j-1}+\left(I F P B^{j-1} \times A C C R H A B\right) \times U_{t}^{i f p b}$

$A C C R H A B$ : rate of habitat change growth. In the absence of data on the growth rate of the housing evolution, the value will be obtained directly from the budget regression line (IFPB heading for the ex-post years considered).

$U_{t}^{i f p b}$ : middle rate of the IFPB

The ground always remains stable. Then:

$I F T^{k}=I F T^{j-1}+\left(I F T^{j-1} \times U_{t}^{i f p b}\right) U_{t}^{i f t}$ with the middle rate of the IFT.

of (a): fiscal pression maintaining

- for the elected official or partisan of the current power:

$R F_{k}=\left(\sum_{i=1}^{12} I F P B_{i}^{k}+\sum_{i=1}^{12} I F T_{i}^{k}+\sum_{i=1}^{12} A R F_{i}^{k}+\sum_{i=1}^{12} A R_{i}^{k}\right) \times\left(1+\right.$ tauxfiscal $\left._{k-1}\right)+\sum_{i=1}^{12}$ DOTA $_{i}^{j-1}+Q F^{j-1}$

(17)

- for the elected official or authorizing officer is not a supporter of the current power:

$R F_{k}=\left(\sum_{i=1}^{12} I F P B_{i}^{k}+\sum_{i=1}^{12} I F T_{i}^{k}+\sum_{i=1}^{12} A R F_{i}^{k}+\sum_{i=1}^{12} A R_{i}^{k}\right) \times\left(1+\right.$ CLtauxfiscal $\left._{k-1}\right)+Q F^{j-1}$

from (b): slowdown technics and learning phase. In the context of the recipes, the equations of (b) are identical to that of (a).

from (c): infra-annual period of the electoral cycle

The other tax revenues will follow the trend of economic growth hoped for by the central state (these are the revenue shares towards the tax center services: additional cent, share on synthetic tax, ...).

$\begin{aligned} \sum_{i=1}^{12} A_{i}{ }^{k} & =\sum_{i=1}^{12} A_{i}{ }^{k}+\left(\sum_{i=1}^{12} A_{i}{ }^{k} \times{ }_{i} \times \text { OISS }_{k}\right) \\ \sum_{i=1}^{12} A R F^{k} & =\sum_{i=1}^{12} A R F^{k}+\left(1+\text { CROISS }_{k}\right)\end{aligned}$

- for the elected official or partisan of the current power:

$R F_{k}=\left(\sum_{i=1}^{12} I F P B_{i}^{k}+\sum_{i=1}^{12} I F T_{i}^{k}+\sum_{i=1}^{12} A R F_{i}^{k}+\sum_{i=1}^{12} A R_{i}^{k}\right) \times\left(1+\right.$ tauxfiscal $\left._{k-1}\right)+\sum_{i=1}^{12} D_{i}{ }^{j-1} \times\left(1+\right.$ CROISS $\left._{k}\right)+Q F^{j-1}$

- for the elected official or authorizing officer is not a supporter of the current power:

$R F_{k}=\left(\sum_{i=1}^{12} \operatorname{IFPB}_{i}{ }^{k}+\sum_{i=1}^{12} \operatorname{IFT}_{i}{ }_{i}+\sum_{i=1}^{12} A R F_{i}{ }_{i}+\sum_{i=1}^{12} A R_{i}^{k}\right) \times\left(1+\right.$ CLtauxfiscal $\left._{k-1}\right)+Q F^{j-1}(18.3)$

from (d): the equations of (d) are identical to that of (c). The authorizing officer maintains the revenue situation, with a view to promoting the next election, in favor of politics partisan. 


\subsection{The balance of volume and budget sections}

The perverse mechanisms of budgetary programming of the investments by the slant of subsidy inflate resources of the Collectivities Local and influential an unbalance of treasury in case of lack of shortterm financing.

\subsubsection{Balance of the investment section}

The $\sum_{i=1}^{n} R I_{i}^{k}=\sum_{i=1}^{n} D I_{i}^{k}$. In the case where the forecast $\sum_{i=1}^{n} R I_{i}^{k}<\sum_{i=1}^{n} D I_{i}^{k}$, the decentralized local collectivities must opt for the increase of their resources as follows :

either to increase the rate of fiscal pressure $k$, of the point of view of a politics fiscal of the elected ;

$\sum_{i=1}^{n} R I_{i}^{k}\left(1+\left(\right.\right.$ CLtauxfiscal $_{k_{0}}+$ CLtauxfiscal $\left.\left._{k_{1}}\right)\right)=\sum_{i=1}^{n} D I_{i}^{k}$

CLtauxfiscal $_{k_{0}}$ : rate of fiscal pressure of departure

CLtauxfiscal $_{k_{1}}$ : fiscal pressure rate to adjust

- $\quad$ either to maintain the fiscal rate $k$ of the LOLF and to increase resources of the accidental SUB component, that to be-to-say, to search for interior or outside subsidies.

$\sum_{i=1}^{n} R I_{k}^{j}+\sum_{i=1}^{n} S U B_{i}^{k}+S U B_{o}=\sum_{i=1}^{n} D I_{k}^{j}$

$S U B_{0}$ : the subsidy of balance

In the contrary case $\sum_{i=1}^{n} R I_{i}^{k}>\sum_{i=1}^{n} D I_{i}^{k}$, one adjusts the forecasts of the income in relation to the expenses.

During the execution this surplus will be considered like a $Q I_{k}$ hang-over to reports for the exercise $k+1$. We have then

$\sum_{i=1}^{n} D \boldsymbol{I}_{a j}^{k}=\sum_{i=1}^{n} D \boldsymbol{I}_{i}^{k}+\left(\sum_{i=1}^{n} \boldsymbol{R} \boldsymbol{I}_{i}^{k}-\sum_{i=1}^{n} D \boldsymbol{I}_{i}^{k}\right)$

$D I_{a j}^{k}$ : the volume of the expenses adjusted

\subsubsection{Balance of the operating section}

The $\sum_{i=1}^{n} R F_{i}^{k}=\sum_{i=1}^{n} D F_{i}^{k}$.

If $\sum_{i=1}^{n} R F_{i}{ }^{k}<\sum_{i=1}^{n} D F_{i}{ }^{k}$, the decentralized local collectivities must opt for the increase of their resources as follows :

- $\quad$ either to increase the rate of fiscal pressure $k$, dawned of view of a politics fiscal of the elected ;

$\sum_{i=1}^{n} R F_{i}{ }^{k}\left(1+\left(\right.\right.$ CLtauxfiscal $_{k_{0}}+$ CLtauxfiscal $\left.\left._{k_{1}}\right)\right)=\sum_{i=1}^{n} D F_{i}{ }^{k}$

CLtauxfiscal $_{k_{0}}$ : rate of fiscal pressure of departure

CLtauxfiscal $_{k_{1}}$ : rate of fiscal pressure adjusted

- $\quad$ either to maintain the fiscal rate $k$ of the LOLF and to increase resources of the accidental component DOTA, that to be-to-say, to throw back or to do some efforts to get the allocated endowments, for the budgetary period $k$.

$\sum_{i=1}^{n} R I_{k}^{j}+\sum_{i=1}^{n} \operatorname{DOTA}_{i}^{k}+\operatorname{DOTA}_{o}=\sum_{i=1}^{n} D I_{k}^{j}$

$\operatorname{DOTA}_{0}$ : other endowments of working

In the contrary case $\sum_{i=1}^{n} R F_{i}{ }^{k}>\sum_{i=1}^{n} D F_{i}{ }^{k}$, one adjusts the forecasts of the income, in relation to the expenses.

During the execution, this surplus will be considered like a $Q F_{k}$ hang-over to report for the exercise $k+1$.

We have then $\sum_{i=1}^{n} D F_{a j}^{k}=\sum_{i=1}^{n} D F_{i}^{k}+\left(\sum_{i=1}^{n} R F_{i}^{k}-\sum_{i=1}^{n} D F_{i}{ }^{k}\right)$

$D F_{a j}^{k}$ : the volume of adjusted expenditure 
The point of view of reducing the forecast of expenditures is not retained, because the expenditures (or debts) are due, and in order to avoid the swelling of the amount of arrears from year to year $\left(A R R_{k+1}\right.$ to $\left.A R R_{k+n}\right)$. Thus, in the event of non-payment of endowments and subsidies, $A R R_{k}$ will accumulate. This is why these components (SUB and DOTA) are accidental. We have classified them as optional or unstable resources. They can be obtained or paid by the State at an uncertain time. They can also be defined as $a$ variable of the decentralization effect.

\subsection{Management of free funds (or net cash)}

The objective of "optimized free fund management" is to reduce the funds deposited in the Treasury. This is not necessarily about achieving "zero" treasury, but getting as close as possible to it. While a free surplus fund does not always reflect good community management.

The cash management options are formulated according to two assumptions:

- hypothesis 1 (h1): desired transaction cash;

- and hypothesis 2 (h2): precautionary cash.

The number of operations as well as the volume of disbursement from the CTD's treasury increases, if the delay $d t$ (Delay engagement + delay organizer and under organizer + accounting delay) is short.

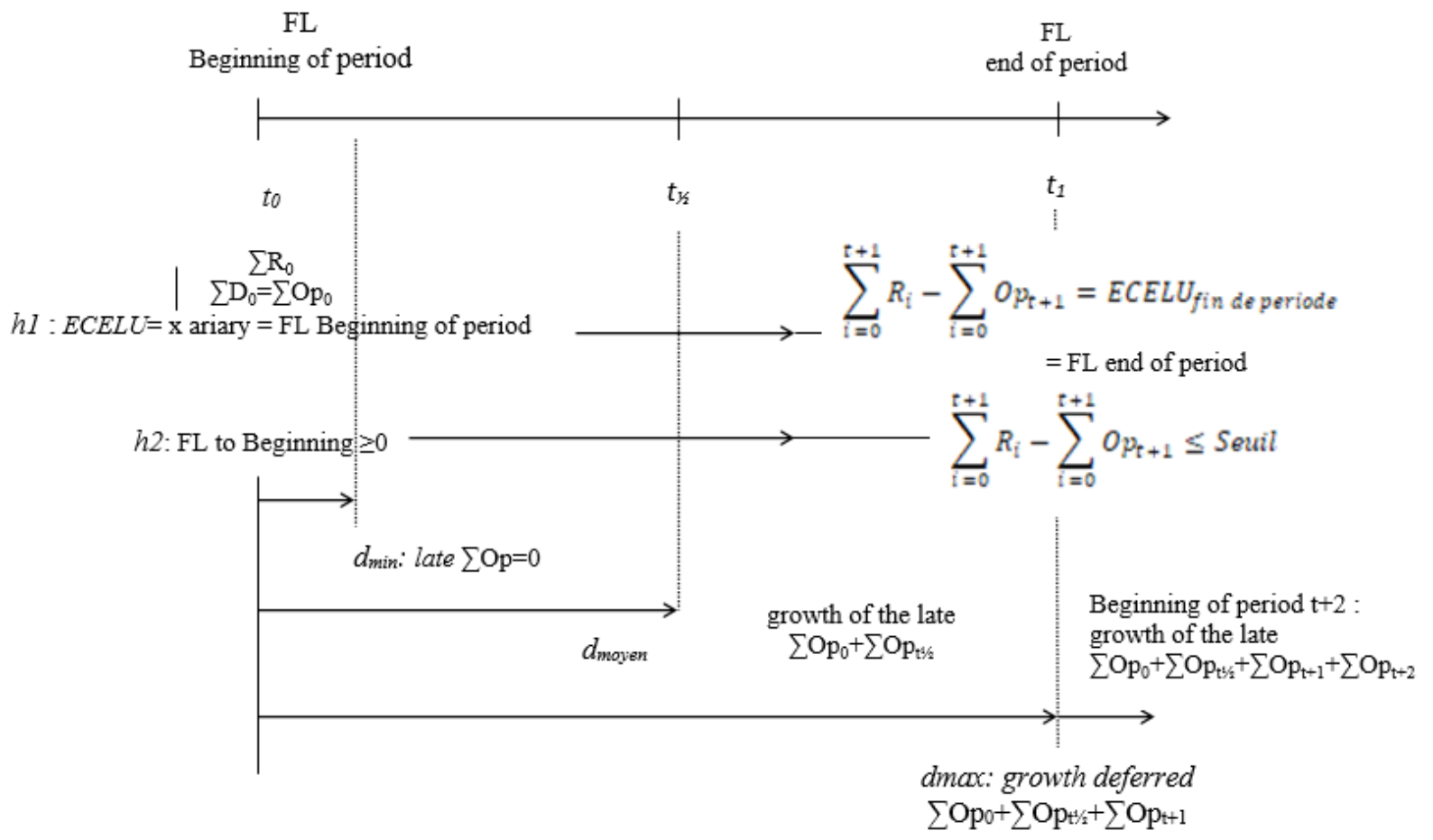

Figure 2. Delai and treasury operations at CTD level

Source: Author, 2018

The maximum time limit $d_{\max }$ modifies the Medium-Term Budget Framework (CBMT) and Medium-Term Expenditure Framework (CDMT) procedure. The results-based management (or GAR) indicators will also be bad and have major impacts on the achievement of the annual work plan (PTA) and the strategic axis of the (Communal Development Plan or PCD). At the end of the year, the $d_{\max }$ stimulates the increase arrears of expenditure, and in return, can influence an investment policy of the elected official. This situation is observed at the level of the CUT, where the net cash is sufficient, and the arrears of expenditure are high, at the end year 2007 (First year of mandate of the elected: raise of the politics investment or growth of the investment expenses), that is to say, reach a certain level of balance transferred to the investment section of year $\mathrm{N}+1$. This budget management technique thus makes it possible to make up for the shortfall in investment resources.

Indeed, boosting the deadline must be considered with rigorous management within the CTD to achieve good budget execution performance.

So, the essential objective will be, therefore, to fix, at all times, the liquidity situation of the Municipality. And, we consider minimum accounting times, the times approaching the average time minus their standard deviation. The maximum accounting times, the times approaching the average time increased by their standard deviation.

The management of the free fund $(F L)$ depends on two options:

- desired transaction treasury;

- and precautionary cash. 
The accumulation of the free fund depends on the delay of pending payment instances and the revenue collected between this period.

$$
\begin{aligned}
& F L_{t}=\sum_{i=1}^{T} R_{i}-\sum_{i=1}^{T} D_{i}, \forall i=1 \ldots T \\
& F L=\underbrace{\left.\sum R-\sum D\right)}+\underbrace{\left.\sum \mathrm{t}_{\text {marge }}^{\text {enciase }} \times R\right)} \\
& \text { Flow Safety margin (gap on free funds } \\
& \text { forecast defined in advance by the elected } \\
& \text { official and error threshold on the } \\
& \text { forecast) }
\end{aligned}
$$

\subsubsection{Free fund to desired transaction cash}

The elected at time t keeps a minimum of treasury. It means that $\sum_{i=1}^{T} D_{i}<\sum_{i=1}^{T} D_{i}$. We have then :

$\sum_{i=1}^{T} D_{i}+E C E L U_{t} \leq \sum_{i=1}^{T} R_{i}$

$E C E L U_{t}$ : difference on free fund defined in advance $E C E L U_{t}>0$ et $E C E L U_{t}<\sum_{i=1}^{T} R_{i}$

At time $t_{1}$, period from to to $t_{1}$, the payment of expenditure is made in order of priority of compulsory expenditure. $\sum_{i=1}^{T} D_{i}$. The free fund is equal :

$F L_{t_{1}}=\sum_{i=1}^{T} R_{i}-\left(\sum_{i=1}^{T} D_{i}+E C E L U_{t_{1}}\right)$

\subsubsection{Free funds in the precautionary fund}

The person elected at time $t$ makes the maximum expenditure without exceeding the existing free fund, that is to say that

$$
\begin{aligned}
& \sum_{i=1}^{T} D_{i} \leq \sum_{i=1}^{T} D_{i} . \\
& F L_{t_{1}}=\left(\sum_{i=1}^{T} R_{i}-\sum_{i=1}^{T} D_{i}\right)+\text { forecast error threshold } \\
& \sum_{i=1}^{T} D_{i}+\text { forecast error threshold } \leq \sum_{i=1}^{T} R_{i} \\
& \text { forecast error threshold } \leq \sum_{i=1}^{T} R_{i}-\sum_{i=1}^{T} D_{i} \\
& \text { Min(forecast error threshold) } \leq \operatorname{Min}\left(\sum_{i=1}^{T} R_{i}-\sum_{i=1}^{T} D_{i}\right)
\end{aligned}
$$

In addition, the availability time of the free fund depends on the different timeframes in the process of collecting revenue and paying expenses.

Let $d_{t}^{\text {eng }}$ : delay of commitment

$$
\begin{aligned}
& d_{t}^{\text {ord }}: \text { delay of authorizing and sub-authorizing } \\
& d_{t}^{\text {compta }} \text { : accounting delay } \\
& d \text { : delay of transaction processing } \\
& d_{i}=d_{t_{i}}^{\text {eng }}+d_{t_{i}}^{\text {ord }}+d_{t_{i}}^{\text {compta }}, \forall i=1, . ., n \text { opérations }
\end{aligned}
$$

The value of $t_{1}=t_{0}+d_{i}, t_{0} \leq t_{1}$ It is possible that the period of operations will be simultaneous (commitment of several expenses, processing and visa of several mandates, payment of several revenue orders, ...). 
In most cases, the additional amount or budget balance from period $k-1$ is charged to the current budget around June (Deliberation period of the City council of the additional budget). It is from this period that it can be considered as a surplus of the treasury fund.

$$
F L_{t_{j}}=\left(\sum_{i=1}^{T} R_{i}-\sum_{i=1}^{T} D_{i}\right)+\mathrm{A} D D I T
$$

with: ADDIT the part of the total additional allocated to operation and ADDIT, the part of the total additional allocated to the investment.

$$
\mathrm{A} D D I T=\sum Q I+\sum Q F
$$

\subsubsection{Effect of delay on treasury authorities}

The salary expense payment transaction increases the number of transactions and the accounting timeframe from the second decade and the first decade of the following month.

For the month of December of each fiscal year, there are few numbers of transactions. It is due to the overcrowding of files at the level of the accounting officer of the CTD in the Treasury. The data is not updated until the end of the additional (The organizers arrange in the yearly beginning of a monthly delay to conduct the broadcast of the titles of perception and the mandates of the corresponding working section to the vested rights and to the services made during the year or the previous years: the complementary period or the complementary day. It doesn't exist of complementary period for the expenses of investment. The complementary day permits the compatibilization in the management that ends, of the last exercise operations) day (on January $15 \mathrm{~N}+1$ ). This working method modifies the treasury (" [...] The deletion of the complementary day appears like a measure presenting several advantages. It cleared, indeed, on a better budgetary execution rate and a surrender of the faster accounts. Indeed, the establishment of the administrative accounts and the accounts of management has can be achieved earlier in the time and permitted a resumption of the faster results otherwise, what improved the management of the territorial collectivities ". source: Jean-Bernard Mattret, "The deletion advantages of the complementary day ", Letter $\mathrm{n}^{\circ} 348$ of November 19, 2015,139309.html?edition=9233, consulted the 15/10/2016) structure of the APUL and influences the anticipated management of incurred expenses (payment of additional expenses in year $\mathrm{N}+1$ mandated and attached to year $\mathrm{N}$ ).

The payment transaction may also generate an injunction for expenditure already deemed unacceptable at the level of control and approval by decision-makers (availability of additional time for rectification and provision of supporting documents). In addition, the working capital (the sum of the cumulative results of the operating and investment sections) will also be wrong; that is to say that the working capital is calculated from the mandates and securities issued by the community in question during a financial year, whereas the treasury results from the difference between the receipts and the disbursements of the 'year. Thus, if the local authority has issued receipts whose amounts have not yet been collected by the accountant (still to be collected), or money orders not yet disbursed (still to be paid). These sums are already included in the working capital, while they are not yet taken into account in the treasury.

\subsection{The lever specific to local authorities}

The freedom of the partisan authorizing officer accessing the social recruitment process reduces the municipalities' room for maneuver with regard to operating expenses. The excessively high wage bill obliges the authorizing officer to minimize other operating expenses. Thus J. Daniel, J. Davis, M. Fouad and C. Van Rijckeghem, 2006, in the work Budget adjustment as an instrument of stability and growth, " [...] The exact volume of budgetary adjustment depending on the circumstances, fiscal policy has more room for maneuver to directly achieve development goals. (...) In industrialized countries, lasting reductions in spending generally relate to the wage bill, subsidies and transfers (Alesina and Perotti, 1997). Evidence also shows that emerging market economies characterized by abundant revenues or low levels of subsidies and transfers are the most likely to achieve consolidation. Likewise, developing countries which reduce certain operating expenses while preserving their investments manage to consolidate their public finances in the long term ". A slowdown in activity is observed and sometimes the lack of cash to support these compulsory expenses. During the fiscal year, they will therefore be forced to make adjustments to support these expenses. So, the important part of the decisions concerning their personnel expenses however rests with the local authorities themselves. By J. Daniel, J. Davis, M. Fouad and C. S. Rijckeghem (2006), "[...] The strategies of reform decentralized aim have modified the structure of the incitements (liberty of the decisions of enrollment, layoff and remuneration, budgeting centered on the results and assessment of the settings). Success of a reforms decentralized pass necessarily by a responsibility and a total transparency".

The proper lever then consists of controlling compulsory short-term expenditure, in order to manage the variation in the flow of free funds, to avoid a short-term funding shortfall.

$$
F L_{t}=\sum_{i=1}^{T} R_{i}-\left(\sum_{i=1}^{T} D O_{i}+\sum_{i=1}^{T} A D_{i}\right)
$$

The margin of operation is written 


$$
\begin{aligned}
& \sum_{i=1}^{T} R_{i}-\sum_{i=1}^{T} D O_{i}=t^{m \arg e} \times \sum_{i=1}^{T} R_{i} \\
& t^{m \arg e}=\frac{\sum_{i=1}^{T} R_{i}-\sum_{i=1}^{T} D O_{i}}{\sum_{i=1}^{T} R_{i}} \\
& t^{m \arg e}=1-\frac{\sum_{i=1}^{T} D O_{i}}{\sum_{i=1}^{T} R_{i}}, \text { avec } \sum_{i=1}^{T} D O_{i} \leq \sum_{i=1}^{T} R_{i}
\end{aligned}
$$

\section{Conclusion}

The decentralization process aims to expand the fiscal space, by improving the efficiency of public spending, but also by mobilizing additional public resources. The own local resources of the decentralized communities constitute an essential component of the resources, which it is possible to mobilize at the level of the decentralized communities.

For several years, Malagasy local authorities have been confronted with various organizational and accounting problems, calling into question in particular their ability to control public expenditure and local risks. G. Chambas, J-F. Brown and G. R. Graziosi (2007), "[...] The weak mobilization of local own resources stems from economic policy decisions which in a large number of countries are reflected in a negative decentralization effort. This result marks a reluctance of central governments to authorize the mobilization of own local resources. Besides the intervention of political factors linked to power games, one explanation for this reluctance may be the current low efficiency of local public spending. The influence of particularly pressing budgetary needs at the central level cannot also be excluded. Finally, the weak mobilization of own local resources stems from global factors (weak public governance, accumulation of public arrears, high incidence of poverty, possible demobilizing effect of certain forms of external aid). It is necessary to take into account all of these factors to promote a stronger mobilization of local own resources."

While putting the priorities fixed by the government and its bets in implementation require a followup assuring that the execution of the budget is in conformity with the policies defined at the time of the cycle of the electorate and to the regulations in force. In this context, the concept of local or territorial governance aims as well to rationalize the shapes of territorial management that to permit to drive efficient economic actions and to constitute effective territories.

By setting the priorities set by the government and its implementation, requires monitoring to ensure that the execution of the budget complies with the policies defined at the time of the electoral cycle, and with the regulations in force. A. Guengant (1985), "[...] The effect of the" electoral cycle "is easily identifiable on the evolution curve of expenditure and local fiscal resources, which constitutes important empirical proof of the existence of a real political effect on the dynamics local public finances. P. Erik Mouritzen (Toulouse, 1993). An effect of this type has been found in other countries".

To ensure budgetary stability, a reliable forecast must be carried out, while using the new contributions of advanced decision-making tools (techniques of gap analysis, ratios, evaluation of results, statistical and econometric tests, operational research ,...). That is why, E. Z. GOÑI (2003) " [...] the strategy of application of the budgetary reform requires a bigger political support even though the organizational context is favorable. The insufficiency of available capacities to manage the change and the hierarchical and formalistic approach of the reform can also explain its limited success. The conclusion to pull is not that the model of budget proposed will always be useless or maladjusted even though the strategy is just. This type of budgetary model could be adapted to a context of stability or increase of resources. It won't be applicable in a context of uncertainty (emergent policies, ambiguous or contradictory opinions on the objectives, difficulty to measure the performances, relation of reason to effect badly surrounded between the project and its effects, ...)". In the OECD report (2003), E. Z. Goñi underlines that "[...] In Spain, as in other countries of continental Europe, the traditional formalist approach predominates1 in the functioning of public administration. Those responsible for managing public expenditure attach paramount importance to the legality of expenditure procedures and to "monitoring" compliance with regulations. Revenue-oriented budgeting has reinforced the orientation towards formalistic control. Approximately until the adoption of the Democratic Constitution in 1978, Spain, although a relatively prosperous country, used revenue-based budgeting" techniques in budget design and financial management.

For Richard Gunther, the explanation for this paradox lies in the fact that the Spanish government did not want or could not increase taxation which led to an erosion of public investments and an estimate of expenditure on the basis of revenue collected. This mode of budgeting created rigidities and reinforced rigorous expenditure control. When budget design is revenue-oriented, the main purpose of budget activity 
and financial management is to control bureaucratic behavior in the public sector, which is small and has a relatively low level of expenditure. high, conforms. " [...] Results-based budgeting is an ideal model to facilitate improved management performance. Results-based budgeting is seen as the only solution valid for the entire public service and explains the choice of a uniform budget and management model. E. Z. Goñi (2003)". Hence a need to study explanatory models. The goal is to come up with a budget simulation model.

\section{References}

1. Abecassis, P. (1992). The cash management behaviors of local authorities, Doctoral thesis in economics, University Paris X-Nanterre, December 1992, p. 158, 543 pages.

2. Bouinot, J. (1997). The new municipal management, Accounting and public management, Cujas; 1st edition, Paris, p. 104, 263 pages.

3. Chambas, G., Brun, J. F., Grégoire, R. G. (2007). The mobilization of local own resources in Africa, "Decentralization and local governance" Forum, United Nations, Viennes, June 22, p. 23, 27 pages.

4. Daniel, J., Davis, J., Fouad, M., Van Rijckeghem, C. (2006). Fiscal adjustment as an instrument of stability and growth, IMF, Brochure Series, $N^{\circ} 55-F$, Washington, p. 35-36, 88 pages.

5. Derycke, P. H., Gilbert, G. (1988). Local public economy, Economica, Paris, p.17, 307 pages.

6. Gilbert, G. (2001). The finances of decentralized communities and financial relations between levels of communities in France: Trends and perspectives, Symposium organized by the Commission on Fiscal Imbalance, September 13 - 14, Quebec, 2001, p.13, 30 pages.

7. Gilbert, G., Vaillancourt, F. (2013). Budgetary balance and solvency of local authorities in a decentralized environment: What lessons can be drawn from national experiences?, French Development Agency, Working Document n ${ }^{\circ} 132$, Paris-France, p. 64, 94 pages.

8. Gillouard, A. (1982). Econometric analysis of a municipal investment function, Communication to the round table on local public finances of CEREVE, November 25, 1982, University Paris-Nanterre, 20 pages.

9. Gillouard, A. (2002). Local finance economics: Thirty-five years of research at CREFAUR, Regional \& Urban Economy Review (RERU), Vol. 2002/5, pp. 687 - 706.

10. Goñi, E. Z. (2003). Results Oriented Budget in Spain: Lessons Learned after Two Decades of Reform, OECD, 2003, p. 20, 24 pages. https://www.oecd.org/fr/espagne/2497156.pdf, consulted on 09/11/2016.

11. Guengant, A. (1984). A macroeconomic model of the evolution of the municipal sector - 1955-1979, CREFAUR, Contrat DGRST, Rennes, 228 pages.

12. Guengant, A. (1984). Territorial Equity and Inequality, LITEC-GRAL, 1983 and its annual chronicles in The Directory of Local Authorities, 1985, LITEC. Hualdeborde JM, the fiscal policies of the municipalities, room for maneuver and maneuver at the margin, Public Policies and Management, 4.

13. Kant, J. D. (2012). Contributions of mathematics and computer science for modeling in the human and social sciences, Mathematics and social science, No. 197, p. 48, pp. 47-64.

14. Mouritzen, P. E. (1993). Does Politics Matter? Does Money Matter? Observations from 15 years in the Treadmill, communication to the AIS World Congress, Madrid, 1990. Quoted by Jean-Yves NEVERS, "Municipalities and innovation, the influence of the renewal of municipal teams on local policies", CERTOP - Center for Technical Studies and Research, Organizations, Powers, Colloque Innovation et Société, Toulouse, p. 6, 20 pages. 